\title{
Bacteriophage Encapsulation Using Spray Drying for Phage Therapy
}

\author{
Danish J. Malik \\ Chemical Engineering Department, Loughborough University, Loughborough \\ LE11 3TU, UK
}

Corresponding author: d.j.malik@lboro.ac.uk

DOI: https://doi.org/10.21775/cimb.040.303

\begin{abstract}
Exploiting the potential of bacteriophages for phage therapy is an exciting future prospect. However, in order to be successful, there is a pressing need for the manufacture of safe and efficacious phage drug products to treat patients. Scalable manufacture of phage biologics as a stable solid dry powder form is highly desirable and achievable using the process of spray drying. Spray drying of purified phage suspensions formulated with suitable excipients can be carried out in a single step with high process throughput and at relatively low cost. The resulting phage-containing powders can possess good storage shelf-life. The process allows control over the final phage dose in the powder and production of microparticles suitable for a variety of therapeutic uses. Spray dried powders may include different polymer formulations employing a multitude of different triggers for phage release at the target site including $\mathrm{pH}$, enzymes, virulence factors etc. The activity of the phages in spray dried powders is adversely affected during spray drying due to dessication and thermal stresses which need to be controlled. The choice of polymers, excipients and moisture content of the dry powders affects the material glass transition temperature and the stability of the phages during storage. The storage temperature and storage humidty are important factors affecting the stability of the phages in the dry powders. A quality by design $(\mathrm{QbD})$ approach for phage drug product development needs to identify drug product characteristics that are critical to quality from the patient's perspective and translates them into the critical quality attributes (CQA) of the drug product. The relationship between the phage drug product CQAs and formulation development and spray drying process conditions are discussed in this article.
\end{abstract}

\section{Introduction}

Phage drug products need careful formulation development and an appreciation of the chemical and physical stresses that bacteriophages may encounter both 
during processing as well as during storage once formulated needs early consideration. Phage inactivation and long-term reduction in phage titres upon storage is highly undesirable. Delivery of high titres of phages and their controlled release at the site of treatment affects phage pharmacokinetics (Malik et al., 2017). The physical and chemical properties of the materials used in the formulation need careful consideration when selecting a technique for encapsulation. Many techniques and processes may be used for stabilising, immobilising and encapsulating phages including spray-drying, spray freeze drying, freeze drying, extrusion dripping methods, emulsion and polymerisation techniques (Malik et al., 2017). Phages are protein structures and they are therefore susceptible to factors known to denature proteins; these include exposure to organic solvents (Lee and Belcher, 2004; Puapermpoonsiri et al., 2009), high temperatures (Briers et al., 2008), pH (Briers et al., 2008; Knezevic et al., 2011), ionic strength (Knezevic et al., 2011) and interfacial effects. Additionally, mechanical stresses during formulation or encapsulation including shear stresses during mixing and agitation, atomisation during spraying (Leung et al., 2016) and, desiccation stresses during drying (Dini and de Urraza, 2013), need careful consideration. Scalable low-cost processes that are compliant with current Good Manufacturing Practices (cGMP) are needed for phage encapsulation.

\section{Spray Drying of Bacteriophages}

Spray drying processes atomise a liquid containing dissolved solids, converting it into a fine mist or aerosol which is contacted with a hot dry gas (typically hot dry air) inside a drying chamber (Figure 1). Due to the high surface area to volume ratio of the very small atomised droplets (droplet size typically $10-100 \mu \mathrm{m}$ ), the solvent rapidly evaporates with each droplet forming a particle comprising the non-volatile components (solids fraction in feed containing bacteriophage and excipients) along with a small amount of residual moisture. The particles are separated from the airstream exiting the dryer, and cyclones or bag filters are typically used for this. Spray drying is a scalable industrial process technology and is widely used to produce fine powders containing biologicals for pharmaceutical applications including pulmonary delivery via dry powder inhalers (DPI) (Hoe et al., 2014) (Figure 2). Dry powders are increasingly being considered for phage drug products because they show relatively long storage stability without requiring a cold supply chain and refrigeration (Carrigy et al., 2019; Chew and Chan, 2002; Klingler et al., 2009). Spray drying of phages using formulations containing synthetic polymers may allow in a single step their encapsulation whilst incorporating targeted delivery and controlled release aspects such as triggered release in response to $\mathrm{pH}$ changes e.g. for gastrointestinal delivery (Vinner et al., 2019). The powders may also be filled into capsules or compressed into oral solid dosage tablets for ease of administration and compliance by patients (Vinner et al., 2019).

\section{Spray drying of phage biologicals using a Quality-by-Design approach}

Quality-by-design is a concept pioneered by Joseph Juran and is based around the concept that quality should be designed into a product rather than relying on end-of-pipe testing (Juran, 2008). A high-quality phage drug product needs to be safe and efficacious, delivering the therapeutic benefit promised to the consumer 


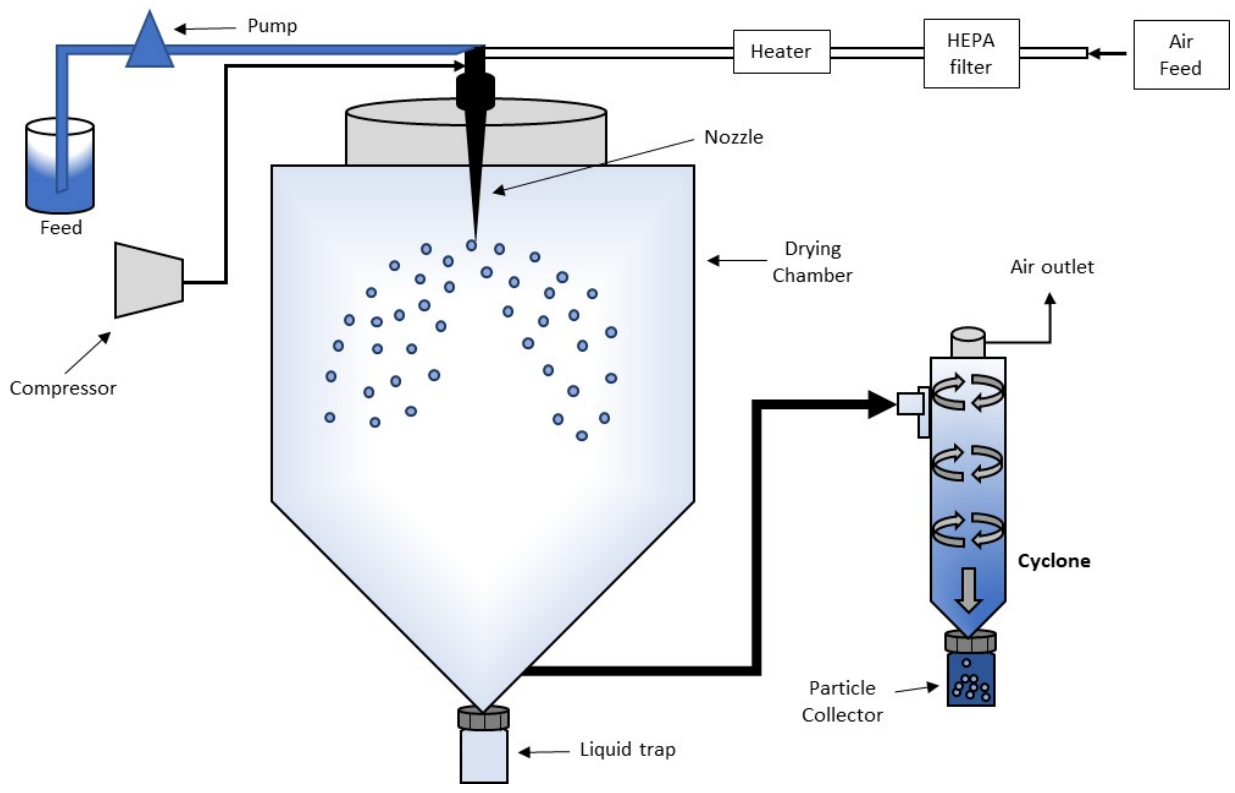

Figure 1. Schematic diagram illustrating a typical spray drying set-up to produce phage powders.

on the product label. Regulators such as the US Food and Drug administration (US FDA) encourage manufacturers to adopt a risk-based approach using QbD principles for drug product development, manufacturing and regulation (Yu et al., 2014). A QbD-led approach emphasises a deep understanding of the manufacturing process and linking product quality to the desired clinical performance of the drug product. Designing a robust formulation and manufacturing process for phage drug products that consistently delivers the desired product quality is essential for the future of phage therapy. Performancebased quality specifications are critical in ensuring this is achieved. Improved product and process understanding helps in designing control strategies to ensure the drug product quality remains within acceptable limits without compromising safety and efficacy. Spray drying of phage biologicals requires identification of process and product characteristics that are critical to product quality from the patient's perspective. These then need to be translated into critical quality attributes (CQAs) of the phage drug product. Linking formulation and manufacturing aspects to CQAs is vital in ensuring the phage drug product meets performance quality criteria. This requires defining what the phage biological's quality target product profile (QTPP) looks like and linking it to CQAs. Identification of critical material attributes (CMAs) (explained below) that are relevant to spray drying of phage biologicals needs to be ascertained as well as critical process parameters (CPPs) specific for the spray drying process. Implementation of process control strategies and accounting for variability in 


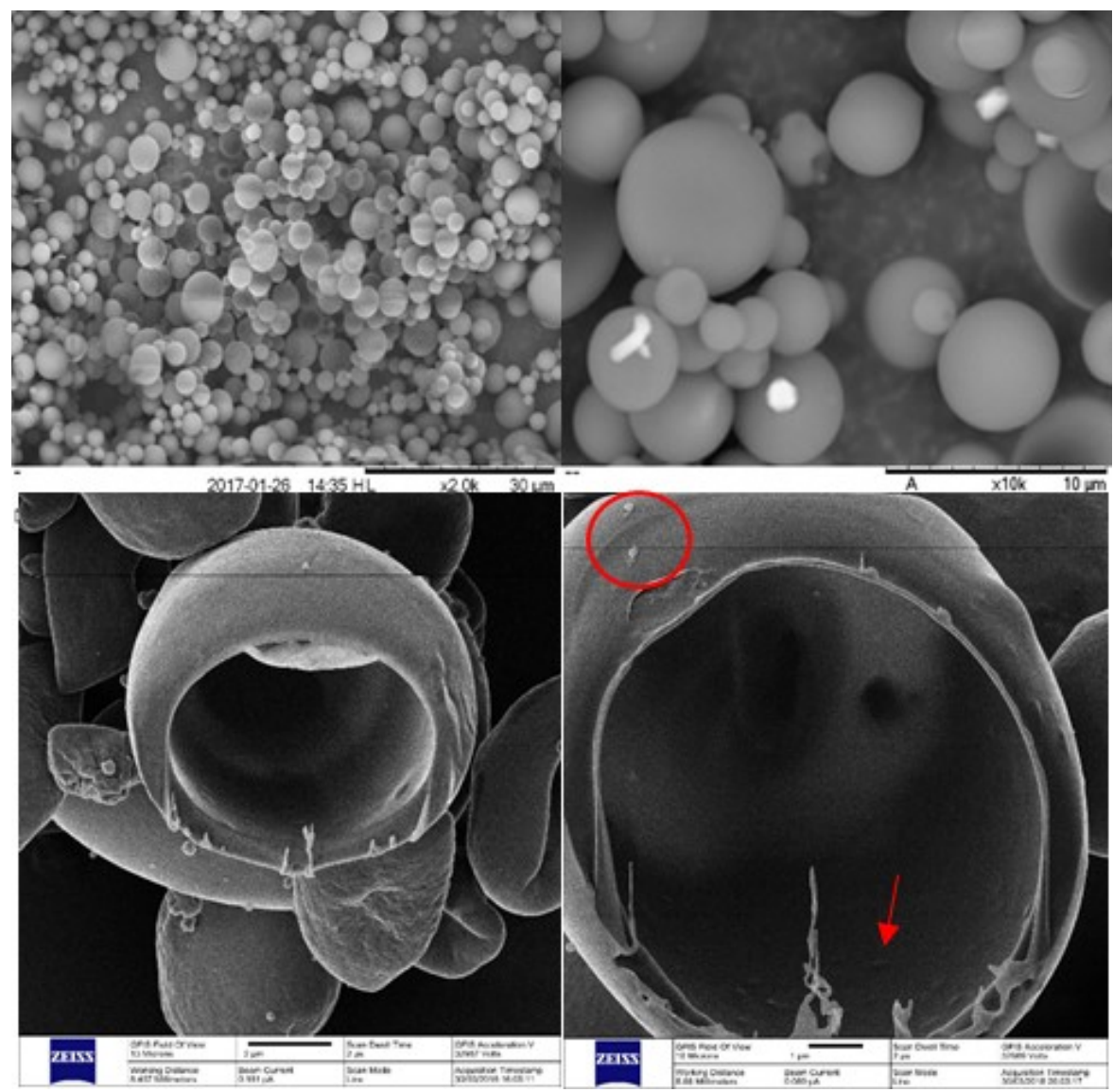

Figure 2. Scanning Electron Microscopy (SEM) images of spray dried phage-containing powders dried at an outlet temperature of $80^{\circ} \mathrm{C}$ using a bench-top spray dryer employing a 2-fluid nozzle for liquid atomisation. The arrow and circle indicate embedded myoviridae phage particles in the core-shell structure of the microparticles.

process inputs as well as putting specifications on CMAs and the drug substance, excipients and drug products is needed (Yu et al., 2014).

The QTPP of the phage drug product is the basis for the phage drug product development and is a summary of all the quality attributes that the drug product needs to meet to ensure it is safe and efficacious (Yu et al., 2014). Identification of the phage drug product's CQAs is the next step and includes many attributes including phage titre in the powder, the powder moisture content, the material's glass transition temperature etc (see summary Table 1). The QTPP of new phage drug products needs to be adequately defined before drug product development work commences. A focus on the phage product design is just as important a consideration as that of process design. The stability of the phage drug product throughout its shelf life needs to be confirmed through stability studies. The key 
Table 1. Typical input material attributes, process parameters and quality attributes of spray dried phage powders.

\begin{tabular}{|c|c|c|}
\hline Input material attributes & Process parameters & Quality attributes \\
\hline $\begin{array}{ll}\text { - } & \text { Phage type e.g. } \\
\text { Myoviridae } \\
\text { Intrinsic } \\
\text { susceptibility of } \\
\text { phage drug } \\
\text { candidate to spray } \\
\text { drying process } \\
\text { stresses including } \\
\text { atomisation, drying, } \\
\text { desiccation, } \\
\text { osmotic and re- } \\
\text { hydration stresses } \\
\text { - } \quad \text { Excipient type e.g. } \\
\text { sugars, polymers, } \\
\text { proteins } \\
\text { - Solution viscosity } \\
\text { - Solution solids } \\
\text { content w/v\% } \\
\text { - } \quad \text { Phage titre } \\
\text { Lysate purity }\end{array}$ & $\begin{array}{ll}\text { - } & \text { Drying } \\
\text { temperature } \\
\text { - } & \text { Drying air gas } \\
\text { flow rate } \\
\text { - } & \text { Liquid feed } \\
& \text { flowrate } \\
\text { - } & \text { Type of atomiser } \\
\text { affecting droplet } \\
\text { size and drying } \\
\text { rates e.g. two } \\
\text { fluid nozzle (and } \\
\text { nozzle size), } \\
\text { rotary wheel } \\
\text { (and rotation } \\
\text { speed). } \\
\text { Dryer residence } \\
\text { time } \\
\text { Cyclone } \\
\text { collection } \\
\text { efficiency } \\
\text { (affects yield of } \\
\text { material) }\end{array}$ & 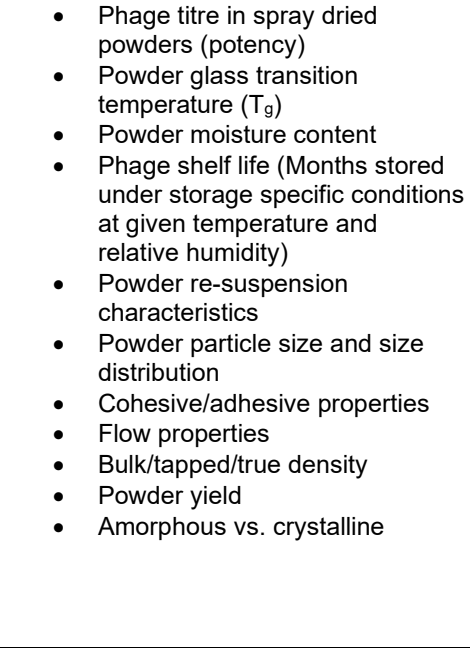 \\
\hline
\end{tabular}

objective of product design is to ensure that the phage drug product retains the desired QTPP over the product shelf life (Yu et al., 2014). Failure of a recent phage therapy clinical trial due to a complex liquid phage drug product suffering storage stability issues during the trial is a valuable lesson for the future (Jault et al., 2018). Key aspects related to CMAs and CQAs for dry powder phage biologicals relevant to spray drying of phage formulations are discussed below.

The role of excipients in stabilising spray dried bacteriophage drug products Spray drying of phage suspensions typically includes excipients in the formulation to protect the phages from thermal and desiccation stresses. The critical material attributes (CMAs) of excipients used in spray drying needs careful consideration. Trehalose, sucrose and lactose have emerged as the most promising excipients for spray drying phage suspensions with trehalose being the front runner due to its high glass transition temperature and water replacement properties (Grasmeijer et al., 2013). Trehalose is the most frequently reported excipient used in the spray drying of phages and it has been shown to result in spray dried powders with high phage titre and good storage stability (Carrigy et al., 2019; Leung et al., 2016, 2017; Matinkhoo et al., 2011; Vandenheuvel et al., 2014). Upon spray drying, sugar excipients form amorphous structures with high glass transition temperatures $(\mathrm{Tg})$, e.g. in their anhydrous amorphous form $\mathrm{Tg}$ of trehalose is $115^{\circ} \mathrm{C}$ and $\mathrm{Tg}$ for lactose is $108{ }^{\circ} \mathrm{C}$ (Chang et al., 2019; Chen et al., 2000; Roe and Labuza, 2005). Below the glass transition temperature, vitrification due to the excipient stabilises the encapsulated bioactive agent and permits storage over long periods at ambient or lower temperatures (Carpenter and Crowe, 1988; Leung et al., 2017). Trehalose has low toxicity and has been shown 
to protect biological materials including proteins, probiotics and vaccines, against desiccation and thermal stress. Crowe et al. (Crowe et al., 1996) suggested that the efficacy of trehalose as an excipient in drying is partly due to its high glass transition temperature at all water contents but also because trehalose binds residual water left over from the drying process to form a dihydrate which might otherwise participate in lowering the glass transition temperature to below ambient (Vandenheuvel et al., 2014). In the amorphous state, trehalose may stabilise protein conformation through hydrogen bonding (Allison et al., 1999). Other excipients that have been used to improve the dispersibility of spray dried phage containing powders include dextrans, lactose (common excipient used for DPI powders), glucose, sucrose, mannitol and, leucine (Leung et al., 2016; Matinkhoo et al., 2011; Telko and Hickey, 2005; Vandenheuvel et al., 2013b). Sugars such as lactose may be unsuitable excipients for bacteriophages due to their reducing properties and hygroscopic nature (Vandenheuvel et al., 2013b). Alternatives such as mannitol have been suggested in the literature however, mannitol has a tendency to recrystallize rather than remaining amorphous (Steckel and Bolzen, 2004). Phage spray drying studies using mannitol have reported improved particle dispersion characteristics however, phage viability results have been mixed (Leung et al., 2016, 2017). Addition of proteins e.g. casein in combination with trehalose have shown good results attributed to protection of phages from thermal stress (Matinkhoo et al., 2011).

\section{Effect of spray drying conditions on phage viability and shelf life}

The spray drying conditions need to be carefully optimised to ensure viability of spray dried phages in the final drug product. 2-fluid nozzles typically used for atomisation of the phage suspensions for spray drying have been shown to generate shear induced damage and loss of phage titre (Leung et al., 2016; Vandenheuvel et al., 2013b). Phages are highly sensitive to thermal stresses resulting in loss of phage activity at high spray drying temperatures (for co-current dryers, outlet temperatures exceeding $60^{\circ} \mathrm{C}$ ) (Davies and Kelly, 1969; Jończyk et al., 2011). Typically, spray drying studies with phages have employed co-current dryers operating at low outlet spray drying temperatures $\left(\sim 40-50{ }^{\circ} \mathrm{C}\right.$ outlet air temperatures) resulting in higher phage titres in the powders and reduced overall phage losses immediately post spray drying (Leung et al., 2017). High loss of phage titres have been observed at higher spray drying temperatures (Leung et al., 2016; Matinkhoo et al., 2011; Vandenheuvel et al., 2013b; Walbeck, 2013). However, the residual moisture content in the spray dried powders (typically $\sim 5 \%$ $\mathrm{w} / \mathrm{w}$ or more, Figure 3 ) due to low drying temperatures $\left(40-50{ }^{\circ} \mathrm{C}\right.$ dryer outlet temperatures) may result in lowering of the glass transition temperature ( $\mathrm{Tg})$ (Roe and Labuza, 2005). The glass transition temperature of an amorphous pharmaceutical solid is a critical physical property (CQA) which can dramatically influence its chemical and physical stability as well as its viscoelastic properties (Figure 4). Water acts as a plasticiser in spray dried powders which may also adsorb water upon storage due to exposure to a humid atmosphere (Hancock and Zografi, 1994). The Tg of amorphous powders such as trehalose, lactose and sucrose fall dramatically when the powders contain relatively low amounts of moisture due to the plasticization effect of water (Chen et al., 2000; Hancock and Zografi, 1994; Roe and Labuza, 2005). Spray dried phage containing powders 


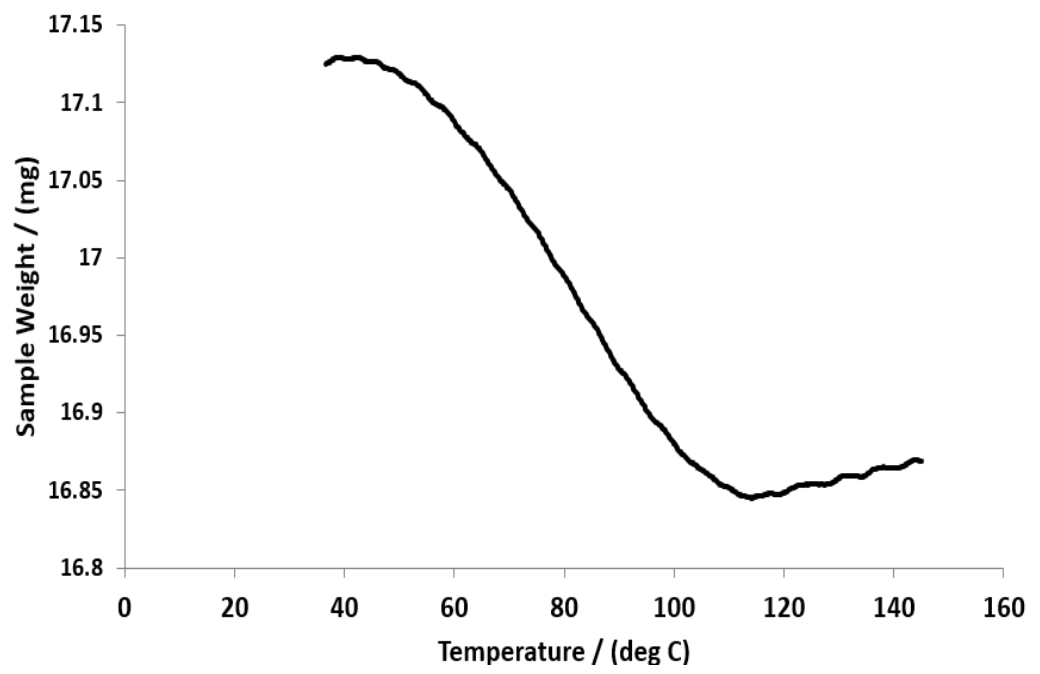

Figure 3. Measurement of residual moisture in spray dried powders using thermal gravimetric analysis (TGA). Spray dried powder produced at an outlet temperature of $65^{\circ} \mathrm{C}$.

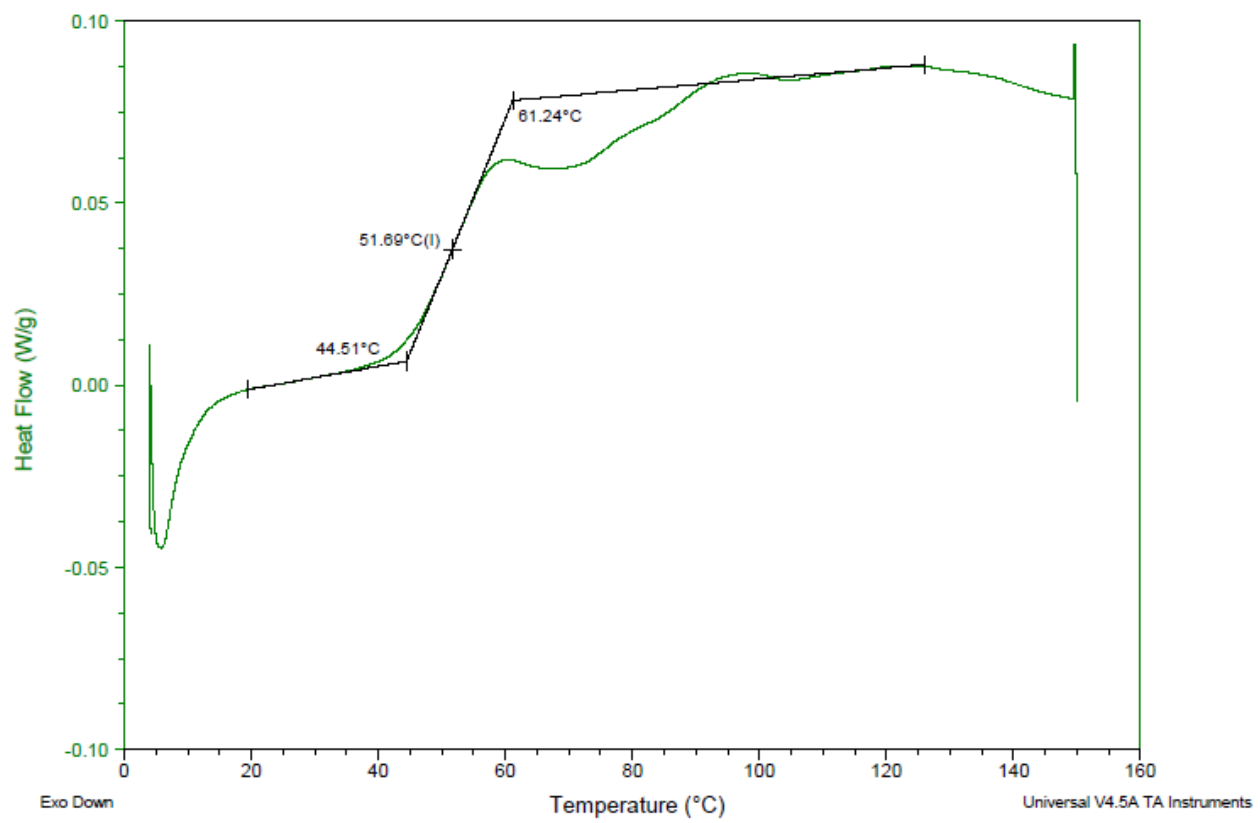

Figure 4. Measurement of glass transition temperature using differential scanning calorimetry (DSC) of a spray dried powder (using trehalose as excipient). Powder produced at an outlet temperature of $65^{\circ} \mathrm{C}$. Onset temperature shown is $45^{\circ} \mathrm{C}$. 


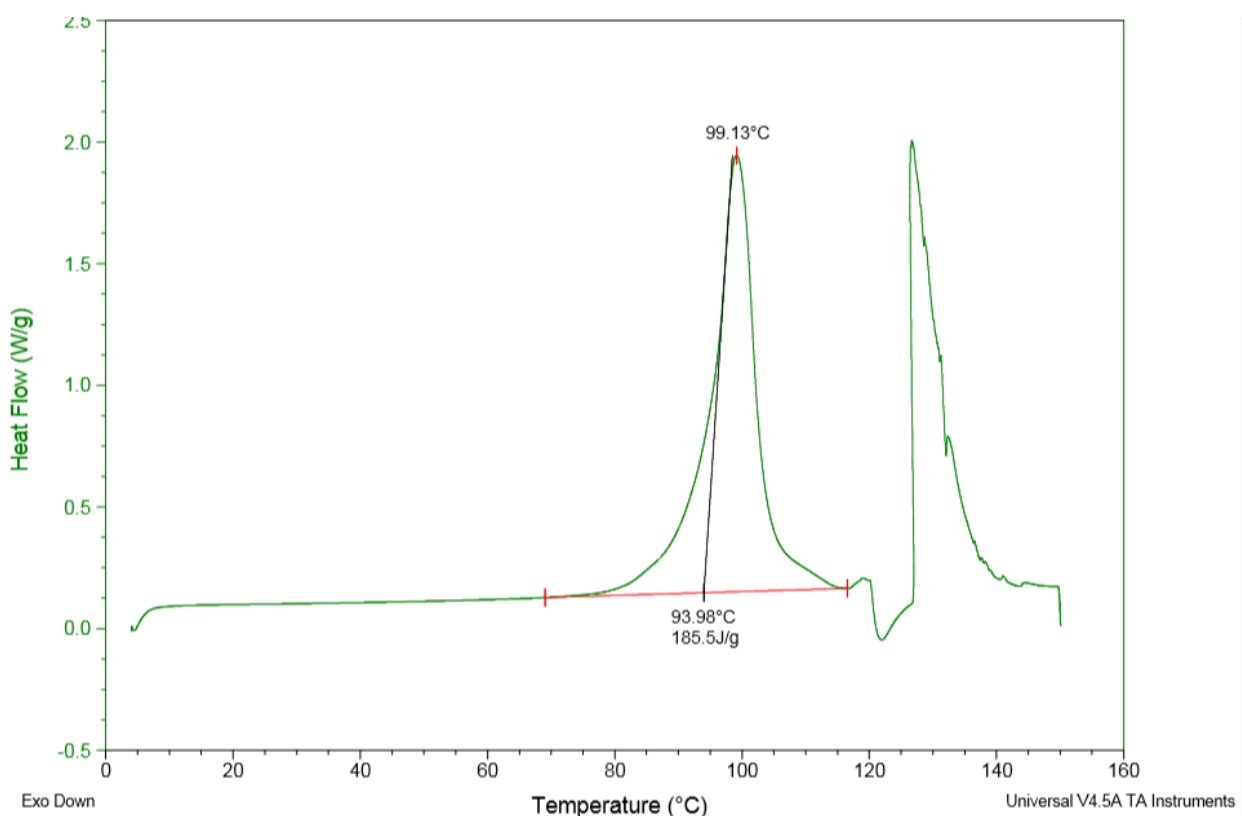

Figure 5. Measurement of glass transition temperature using differential scanning calorimetry (DSC) of a spray dried powder (using trehalose as excipient). Powder produced at an outlet temperature of $65^{\circ} \mathrm{C}$ and exposed to storage conditions of $30^{\circ} \mathrm{C}$ and $65 \%$ relative humidity for 24 hours. Peaks indicate re-crystallisation of the trehalose with endothermic melting peaks for different trehalose polymorphs shown here.

tend to be amorphous upon production however, storage conditions may subject the material to temperatures and humidity conditions lying above the glass transition line. Crystallization rates of glasses depend on the storage temperature in relation to $\mathrm{Tg}$. Recrystallisation of amorphous sugar in spray dried powders negatively affects phage viability perhaps due to denaturing of phage receptor proteins as sugar molecules can no longer interact through hydrogen bonding with proteins to retain protein conformation upon crystallisation (Carpenter and Crowe, 1988; Roe and Labuza, 2005) (Figures 5 and 6). The use of excipients that are hygroscopic e.g. lactose and trehalose also require careful handling under controlled atmospheric conditions and the use of a dry atmosphere controlled glove box is advisable during powder handling to prevent exposure of the dry powder to moisture in the atmosphere (Carrigy et al., 2019; Leung et al., 2017; Matinkhoo et al., 2011).

Effect of storage conditions on phage stability in spray dried powders

Storage temperature and relative humidity are the two main factors shown to affect phage stability in spray dried powders. Amorphous forms of dry powder pharmaceutical biologics are most stable when molecular motion in the disordered state is retarded over a meaningful pharmaceutical timeframe (Hancock and Zografi, 1994). The storage temperature needs to be considerably below the amorphous powder material's $\mathrm{Tg}$ to slow down molecular motion such 

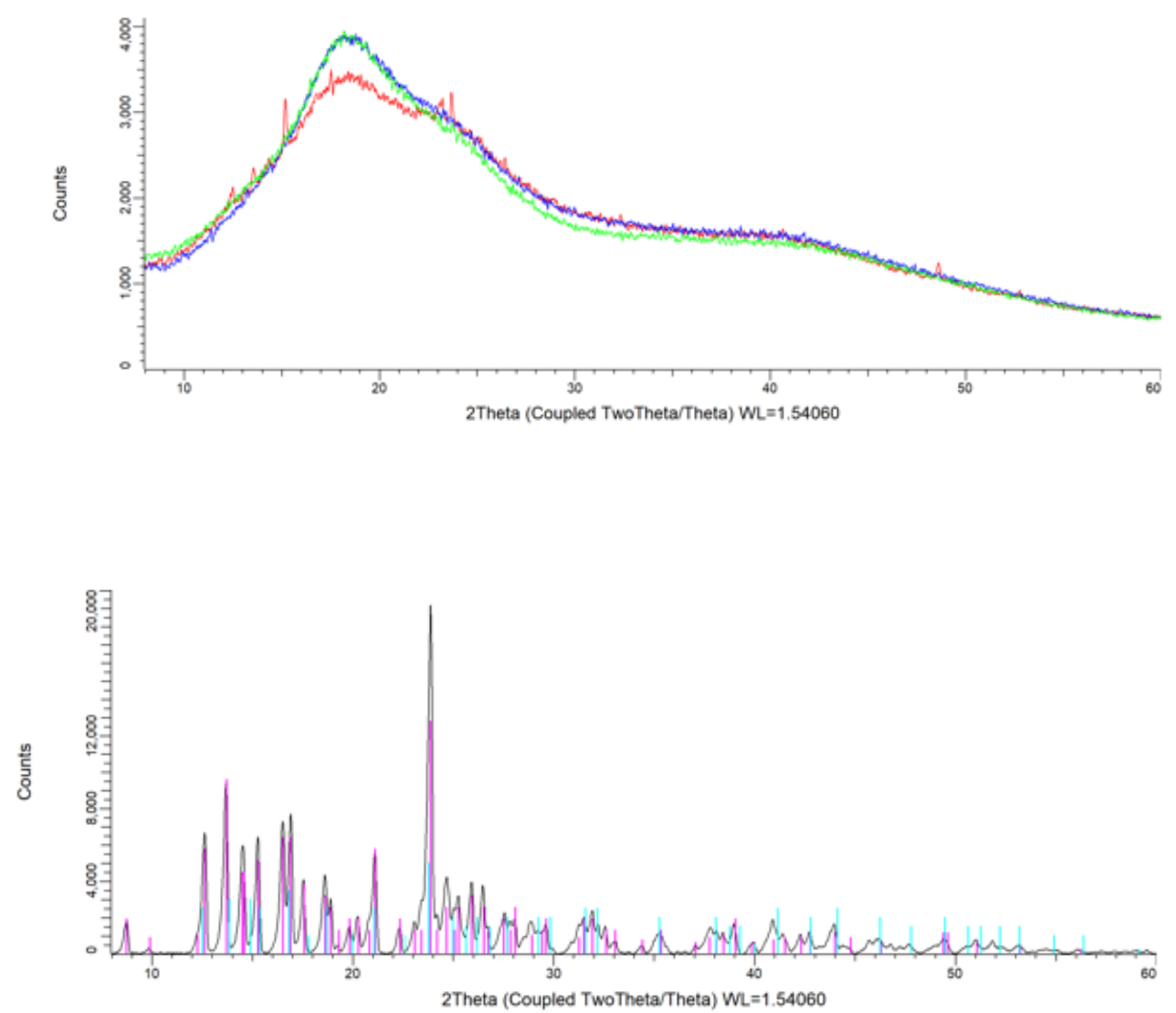

Figure 6. Top Panel: Powder X-ray diffraction results showing amorphous trehalose powders immediately, six months and one year following spray drying at $65^{\circ} \mathrm{C}$ outlet drying temperature and stored at $4{ }^{\circ} \mathrm{C}$ (blue curve (immediately after spray drying), green curve (six months after spray drying) and red curve (one year after spray drying)). Bottom panel: Same sample exposed to storage conditions of $30^{\circ} \mathrm{C}$ and $65 \%$ relative humidity for 24 hours resulting in re-crystallisation of the trehalose.

that chemical and physical instability of the drug product does not occur over the lifetime of the pharmaceutical product, which is typically of the order of a few years (Hancock and Zografi, 1994). Storage temperatures $50{ }^{\circ} \mathrm{C}$ below the glass transition temperature are thought to significantly reduce molecular movement and help in lengthening phage powder storage shelf life (Chang et al., 2020; Hancock et al., 1995). Refrigerated storage of spray dried powders at relative humidity exceeding $20 \%$ has been shown to result in loss of phage titre whereas samples stored at low humidity were stable (Leung et al., 2017; Vandenheuvel et al., 2014). Disaccharides such as trehalose, sucrose and lactose preserve the bioactivity of bacteriophages in the dry state. Refrigerated storage of spray dried powders was reported to yield higher titres of phage during long term storage compared with storage under ambient conditions (Leung et al., 2017). Different phage strains formulated and spray dried under identical conditions showed 
significant differences in the resulting phage titre suggesting the need for individually formulating each phage to be used in a phage cocktail (Vandenheuvel et al., 2013b, 2014). The selection of phages as suitable candidates for phage therapy should include consideration of whether they lend themselves to spray drying i.e. a CMA as part of $\mathrm{QbD}$ approach to linking drug product design to the QTPP if the final drug product is to be delivered to patients in a stable dry powder form. A number of studies have reported spray dried phage powders to have a suitable mass median aerosolized diameter for pulmonary delivery of phages to treat respiratory infections (Leung et al., 2016; Matinkhoo et al., 2011; Vandenheuvel et al., 2013a, 2014). Here the powder particle size is a CQA linking powder aerosolization to QTPP. Such critical issues need greater consideration early in the product design cycle.

\section{Conclusions}

Formulation and stability of phage drug products needs greater consideration during phage drug product design. Spray drying is a scalable, high throughput process, that lends itself to production of stable dry powder phage biologicals. A $\mathrm{QbD}$ approach to phage drug product design is advocated in this review. CMAs include selection of suitable phage candidates at an early stage in drug prodduct design that lend themselves to spray drying and using excipients that result in dry powders suitable for phage biologicals. A better understanding of the critical process parameters related to spray drying and consideration of powder handling, packaging and storage conditions is needed. Spray drying of phage biologicals can increase stability and shelf life of the drug product as well as incorporating targeted delivery and controlled release elements. Spray dried powders can be loaded into capsules or made into tablets using direct compression processes giving added flexibility for ease of use.

\section{References}

Allison, S. D., Chang, B., Randolph, T. W., and Carpenter, J. F. (1999). Hydrogen bonding between sugar and protein is responsible for inhibition of dehydrationinduced protein unfolding. Arch. Biochem. Biophys. 365, 289-298. doi:10.1006/ abbi.1999.1175.

Briers, Y., Miroshnikov, K., Chertkov, O., Nekrasov, A., Mesyanzhinov, V., Volckaert, G., and Lavigne, R. (2008). The structural peptidoglycan hydrolase gp181 of bacteriophage phiKZ. Biochem. Biophys. Res. Commun. 374, 747-751. doi:10.1016/j.bbrc.2008.07.102.

Carpenter, J. F., and Crowe, J. H. (1988). Modes of stabilization of a protein by organic solutes during desiccation. Cryobiology 25, 459-470. doi: 10.1016/0011-2240(88)90054-5.

Carrigy, N. B., Liang, L., Wang, H., Kariuki, S., Nagel, T. E., Connerton, I. F., and Vehring, R. (2019). Spray-dried anti-Campylobacter bacteriophage CP30A powder suitable for global distribution without cold chain infrastructure. Int. J. Pharm. 569, 118601. doi:10.1016/j.jpharm.2019.118601.

Chang, R. Y. K., Kwok, P. C. L., Khanal, D., Morales, S., Kutter, E., Li, J., and Chan, H-K. (2020). Inhalable bacteriophage powders: Glass transition temperature and bioactivity stabilization. Bioeng. Transl. Med., e10159. doi: 10.1002/btm2.10159. 
Chang, R. Y. K., Wallin, M., Kutter, E., Morales, S., Britton, W., Li, J., and Chan, $\mathrm{H}-\mathrm{K}$. (2019). Storage stability of inhalable phage powders containing lactose at ambient conditions. Int. J. Pharm. 560, 11-18. doi:10.1016/j.ijpharm. 2019.01.050.

Chen, T., Fowler, A., and Toner, M. (2000). Literature review: Supplemented phase diagram of the trehalose-water binary mixture. Cryobiology 40, 277-282. doi:10.1006/cryo.2000.2244.

Chew, N. Y. K. ., and Chan, H. K. . (2002). The role of particle properties in pharmaceutical powder inhalation formulations. J. aerosol Med. 15, 325-330.

Crowe, L. M., Reid, D. S., and Crowe, J. H. (1996). Is trehalose special for preserving dry biomaterials? Biophys. J. 71, 2087-93. doi:10.1016/ S0006-3495(96)79407-9.

Davies, J. D., and Kelly, M. J. (1969). The preservation of bacteriophage H1 of Corynebacterium ulcerans U103 by freeze-drying. J. Hyg. (Lond). 67, 573-583. doi:10.1017/S0022172400042030.

Dini, C., and de Urraza, P. J. (2013). Effect of buffer systems and disaccharides concentration on Podoviridae coliphage stability during freeze drying and storage. Cryobiology 66, 339-342. doi:10.1016/j.cryobiol.2013.03.007.

Grasmeijer, N., Stankovic, M., De Waard, H., Frijlink, H. W., and Hinrichs, W. L. J. (2013). Unraveling protein stabilization mechanisms: Vitrification and water replacement in a glass transition temperature controlled system. Biochim. Biophys. Acta - Proteins Proteomics 1834, 763-769. doi:10.1016/j.bbapap. 2013.01.020.

Hancock, B. C., Shamblin, S. L., and Zografi, G. (1995). Molecular Mobility of Amorphous Pharmaceutical Solids Below Their Glass Transition Temperatures. Pharm. Res. An Off. J. Am. Assoc. Pharm. Sci. 12, 799-806. doi:10.1023/A: 1016292416526.

Hancock, B. C., and Zografi, G. (1994). The Relationship Between the Glass Transition Temperature and the Water Content of Amorphous Pharmaceutical Solids. Pharm. Res. An Off. J. Am. Assoc. Pharm. Sci. 11, 471-477. doi: 10.1023/A:1018941810744.

Hoe, S., Ivey, J. W., Boraey, M. A., Shamsaddini-Shahrbabak, A., Javaheri, E., Matinkhoo, S., Finlay, W.H. and Vehring, R. (2014). Use of a fundamental approach to spray-drying formulation design to facilitate the development of multi-component dry powder aerosols for respiratory drug delivery. Pharm. Res. 31, 449-465. doi:10.1007/s11095-013-1174-5.

Jault, P., Leclerc, T., Jennes, S., Pirnay, J. P., Que, Y.-A., Resch, G., Rousseau, A.F., Ravat, F., Carsin, H., Le Floch, R., Schaal, J.V., Soler, C., Fevre, C., Arnaud, I., Bretaudeau, L. and Gabard, J. (2018). Efficacy and tolerability of a cocktail of bacteriophages to treat burn wounds infected by Pseudomonas aeruginosa (PhagoBurn): a randomised, controlled, double-blind phase 1/2 trial. Lancet Infect. Dis. 0, 1-11. doi:10.1016/S1473-3099(18)30482-1.

Jończyk, E., Kłak, M., Międzybrodzki, R., and Górski, A. (2011). The influence of external factors on bacteriophages--review. Folia Microbiol. (Praha). 56, 191-200. doi:10.1007/s12223-011-0039-8.

Juran, J. M. (2008). Juran on Quality by Design: The New Steps for Planning Quality into Goods and Services. Simon and Schuster. 
Klingler, C., Müller, B. W., and Steckel, H. (2009). Insulin-micro- and nanoparticles for pulmonary delivery. Int. J. Pharm. 377, 173-179. doi:10.1016/j.ijpharm. 2009.05.008.

Knezevic, P., Obreht, D., Curcin, S., Petrusic, M., Aleksic, V., Kostanjsek, R., Petrovic, O. (2011). Phages of Pseudomonas aeruginosa: Response to environmental factors and in vitro ability to inhibit bacterial growth and biofilm formation. J. Appl. Microbiol. 111, 245-254. doi:10.1111/j. 1365-2672.2011.05043.x.

Lee, S. W., and Belcher, A. M. (2004). Virus-based fabrication of micro- and nanofibers using electrospinning. Nano Lett. 4, 387-390. doi:10.1021/nI034911t.

Leung, S. S. Y., Parumasivam, T., Gao, F. G., Carrigy, N. B., Vehring, R., Finlay, W. H., Morales, S., Britton, W. J., Kutter, E. and Chan, H-K. (2016). Production of Inhalation Phage Powders Using Spray Freeze Drying and Spray Drying Techniques for Treatment of Respiratory Infections. Pharm. Res. 33, 1486-1496. doi:10.1007/s11095-016-1892-6.

Leung, S. S. Y., Parumasivam, T., Gao, F. G., Carrigy, N. B., Vehring, R., Finlay, W. H., Morales, S., Britton, W. J., Kutter, E. and Chan, H-K.. (2017). Effects of storage conditions on the stability of spray dried, inhalable bacteriophage powders. Int. J. Pharm. doi:10.1016/j.ijpharm.2017.01.060.

Malik, D. J., Sokolov, I. J., Vinner, G. K., Mancuso, F., Cinquerrui, S., Vladisavljevic, G. T., Clokie, M. R. J. Garton, N.J., Stapley, A.G.F. and Kirpichnikova, A. (2017). Formulation, stabilisation and encapsulation of bacteriophage for phage therapy. Adv. Colloid Interface Sci. 249, 100-133. doi: 10.1016/j.cis.2017.05.014.

Matinkhoo, S., Lynch, K. H. ., Dennis, J. J. ., Finlay, W. H., and Vehring, R. (2011). Spray-Dried Respirable Powders Containing Bacteriophages for the Treatment of Pulmonary Infections. J. Pharm. Sci. 100, 5197-5205.

Puapermpoonsiri, U., Spencer, J., and Walle, C. F. Van Der (2009). A freeze-dried formulation of bacteriophage encapsulated in biodegradable microspheres. Eur. J. Pharm. Biopharm. 72, 26-33. doi:10.1016/j.ejpb.2008.12.001.

Roe, K. D., and Labuza, T. P. (2005). Glass transition and crystallization of amorphous trehalose-sucrose mixtures. Int. J. Food Prop. 8, 559-574. doi: 10.1080/10942910500269824.

Steckel, H., and Bolzen, N. (2004). Alternative sugars as potential carriers for dry powder inhalations. Int. J. Pharm. 270, 297-306. doi:10.1016/j.ijpharm. 2003.10.039.

Telko, M. J., and Hickey, A. J. (2005). Dry powder inhaler formulation. Respir. Care 50, 1209-1227. doi:10.2165/00128413-200615470-00016.

Vandenheuvel, D., Meeus, J., Lavigne, R., and Van Den Mooter, G. (2014). Instability of bacteriophages in spray-dried trehalose powders is caused by crystallization of the matrix. Int. J. Pharm. 472, 202-205. doi:10.1016/j.ijpharm. 2014.06.026.

Vandenheuvel, D., Singh, A., Vandersteegen, K., Klumpp, J., Lavigne, R., and Mooter, G. Van Den (2013a). European Journal of Pharmaceutics and Biopharmaceutics Feasibility of spray drying bacteriophages into respirable powders to combat pulmonary bacterial infections. Eur. J. Pharm. Biopharm. 84, 578-582. doi:10.1016/j.ejpb.2012.12.022. 
Vandenheuvel, D., Singh, A., Vandersteegen, K., Klumpp, J., Lavigne, R., and Van Den Mooter, G. (2013b). Feasibility of spray drying bacteriophages into respirable powders to combat pulmonary bacterial infections. Eur. J. Pharm. Biopharm. 84, 578-582. doi:10.1016/j.ejpb.2012.12.022.

Vinner, G. K., Rezaie-Yazdi, Z., Leppanen, M., Stapley, A. G. F., Leaper, M. C., and Malik, D. J. (2019). Microencapsulation of Salmonella-specific bacteriophage Felix $\mathrm{O} 1$ using spray-drying in a $\mathrm{pH}$-responsive formulation and direct compression tableting of powders into a solid oral dosage form. Pharmaceuticals 12, 1-14. doi:10.3390/ph12010043.

Walbeck, A. K. (2013). US Patent, 8501453 B2:Methods for drying bacteriophage and bacteriophage-containing compositions, the resulting dry compositions, and methods of use.

Yu, L. X., Amidon, G., Khan, M. A., Hoag, S. W., Polli, J., Raju, G. K., and Woodcock, J. (2014). Understanding pharmaceutical quality by design. AAPS J. 16, 771-783. doi:10.1208/s12248-014-9598-3. 
